\title{
ESQUEMAS ESTÉTICOS
}

Aura y "aire de familia"

Fabrizio Desideri 


\section{Fabrizio Desideri}

Università degli Studi di Firenze, Italia

\section{Esquemas estéticos: aura y "aire de familia"}

Traducido del italiano por Gastón Giribet (CONICET)

DOI: 10.36446/be.2021.54.219

\section{Resumen}

En las escenas de atención conjunta propias de la temprana infancia, el intercambio emocional con el adulto produce tanto una sintonización atencional (reconocer que el otro dirige su atención a un objeto determinado) como una sintonización intencional (la capacidad de reconocer la intención del otro a compartir la experiencia atencional). Entre el emparejamiento de la atención y la aparición de experiencia ana una intencions espacio autónomo para la conceptualización de proto-experiencias de tenor estético. En este contexto, el presente artículo propone la hipotesis de que el conocimiento del mundo como consecuencia de la orientación cognitivo-perceptiva que florece a partir de los contextos de atención conjunta se lleva a cabo en virtud de una "aire de familia" o "aura" estéticos. Con el propósito de indagar la posibilidad de una especificidad estética de estas proto-experiencias, la argumentación se apoya en las modulaciones de la noción de "esquema" a través del pensamiento de Immanuel Kant, Frederic Bartlett y Marvin Minsky.

\section{Palabras clave}

Experiencia estética; Sintonía afectiva; Sintonía intencional; Esquema-imagen;

Teoría de los marcos

\section{Aesthetic Schemes: Aura and "Family Resemblance"}

\section{Abstract}

In the scenes of joint attention experienced in early childhood, the emotional exchange with the adult produces an attentional tuning (recognizing that the other person directs her attention to a particular object) as well as an intentional tuning (the ability to recognize the other person's invitation to share the attentional experience). Between the pairing of attention and the emergence of a cooperative intentionality arises the possibility of an autonomic space for conceptualizing protoaesthetic experiences. In such context, this article argues that the knowledge of the world, because of the cognitive-perceptive attention that flourishes from contexts of joint attention, is carried out in virtue of an asthetic "family resemblance" or an of joint attention, is carried out in virtue of an aesthetic "family resemblance" or an aesthetic "aura". In order to enquire the possibility of an aesthetic specificity of these proto-experiences, the line of reasoning is based in the modulations of the notion of "scheme" in Immanuel Kant's thoughts, Frederic Bartlett and Marvin
Minsky.

\section{Keywords}

Aesthetic Experience; Affective Tuning; Intentional Tuning; Scheme-Image; Frame Theory

Titulo original: "Schemi estetici: aura e 'aira di famiglia", Origine dell'estetico: Delle emozioni al giudizio (Roma: Carocci editore, 2018), 61-76.

Recibido: 10/06/20. Aprobado: 20/05/21.

\section{ATENCIÓN CONJUNTA, SINTONÍA AFECTIVA Y GÉNESIS DE LOS ESQUEMAS ESTÉTICOS}

1. En el contexto de las escenas de atención conjunta que el niño experimenta alrededor de los nueve meses, ¿cómo se configuran las formas de experiencia estética? ¿Qué valor toman? ¿Qué sucede y se produce con ellas que sea de relevancia para la cuestión del origen de la estética?

Le debemos a Michael Tomasello haber comprendido e insistido en la importancia de las experiencias infantiles de atención conjunta y de las habilidades nuevas y específicamente humanas que estas implican. Sobre la base de numerosas evidencias experimentales, Tomasello ha desarrollado la tesis de que las escenas de atención conjunta marcan la transición, típica del desarrollo infantil, de una interacción diádica (alternativamente con adultos o con objetos) a una interacción triádica, donde dos elementos parecen ser decisivos: por un lado, el desarrollo por parte del niño de la capacidad de una "sintonización atencional" frente a un objeto polo no necesariamente próximo; por otro, el desarrollo de la capacidad de reconocer otros sujetos intencionales con los cuales sintonizar. La sintonización atencional, en breve, significaría "sintonización intencional" en cuanto expresión de interacción socioemocional. Esta última sintonía podría hacerse manifiesta durante los primeros meses de vida, en forma de una "sintonía afectiva" (Tomasello 
2009: 123). ${ }^{1}$ De este contexto de intercambio emocional, de interacciones cara a cara que toman la forma de proto-observaciones, emergería entonces una sintonía más compleja y cognitivamente más densa: la capacidad de reconocer la intención del adulto cuando dirige la propia atención hacia a algo e invita al niño que está frente a él a compartir su experiencia atencional.

2. Dicho en términos más simples e intuitivos, en esta escena de intercambio atencional, el niño descubre que ve lo que otros ven. El suyo se convierte, así, en un co-ver, convidando la visión y, más en general, la dinámica típica de percepción, caracterizada ésta por el intercambio activo con algo más, un recorte del objeto en el espacio-ambiente: un atractor capaz no solo de llamar la atención, sino también de convocar la orientación perceptiva de diferentes sujetos en una misma escena. Con agudeza, Tomasello ve aquí entramarse la primera forma de una intencionalidad compartida como un prerrequisito para el desarrollo de una inteligencia cooperativa. La pregunta a ser formulada es si no se toma demasiado precipitadamente la convergencia entre una "sintonía afectiva" y una "intencionalidad compartida". Sobre la base de tal convergencia, de hecho, la escena de joint attention es considerada en términos de un compartir una actitud intencional. Pero de este modo se descuida la no coincidencia lógica y fenomenológica entre la atencionalidad y la intencionalidad, entre los procesos atencionales y las actitudes intencionales (sobre esta diferencia, véase Desideri 2011: 48 y passim).

Si, por un lado, la atención se configura intencionalmente y, por lo tanto, ciertamente asume en nuestro caso las características de una

\footnotetext{
${ }^{1}$ Tomasello se refiere aquí a la noción de "sintonía afectiva" desarrollada por Daniel Stern en Stern 1985.
}

intencionalidad compartida; por otro lado (precisamente por la naturaleza procesal y gradual del involucramiento atencional), puede activarse de manera autónoma por una actitud intencional. También por esta razón, en todos aquellos casos en los que no está orientado previamente por un interés, la atención surge (o puede surgir) como respuesta a una solicitud externa: al hecho de que un objeto externo a la mente funciona como un atractor de la atención en virtud de su capacidad intrínseca para despertarla.

Manteniendo esta propiedad pre- y meta-intencional de la atención como object-driven, ${ }^{2}$ se abre la posibilidad de que, entre la sintonía afectiva y la aparición de una intencionalidad cooperativa, se abra el espacio autónomo (respondiendo a las leyes inmanentes de su constitución) de una sintonía atencional entre el niño y el adulto que lo cuida, desbalanceado hacia afuera (hacia la terceridad de un objeto polo) y sintonizado afectivamente.

Es, entonces, en el espacio de una sintonía atencional en la frontera de toda intencionalidad que pueden presentarse en la vida del infante proto-experiencias de tenor estético. Formas de experiencia, es decir, donde el impacto perceptivo compartido atencionalmente con los objeto-atractores, o con algunas de sus propiedades elementales pero estéticamente significativas, dejan trazas en la memoria que predisponen a futuros reconocimientos de objetos estéticamente destacados y refuerzan la demanda de reiterar esas experiencias. En otros términos, es en el contexto de aquellas formas especiales de participación emocional que caracterizan en un sentido intercultural las interacciones madre-hijo que se generan proto-formas de experiencia estética con la utilización de objetos, caracterizadas por

${ }^{2}$ Sobre esta caracterización de la atención, véase Hardcastle 1997: 62-63 y Desideri 2011: 40-41. 
el placer de la repetición y la variación. Formas de protoexperiencia estética que generan expectativas y anticipación ante el medio ambiente. Expectativas generadas por la familiarización atencional y post-atencional con objetos próximos y distantes mediante sus propiedades estéticas de bajo nivel: colores saturados, sonidos rítmicamente repetidos, melodías elementales, vocalizaciones exageradas, formas principalmente simétricas y/o protosignificativas en su funcionar como un llamado a la participación bio-afectiva primordial con la madre (comenzando por su rostro).

3. Nuestra tesis, por lo tanto, es que el conocimiento [l'acquaitance] del mundo como consecuencia de la orientación cognitivoperceptiva que florece a partir de los contextos de atención conjunta se lleva a cabo en virtud de una familiarización estética, o el establecimiento de una armonía tanto afectiva como cognitiva con affordances ambientales y objetos que distienden y potencian de manera gratificante el estándar de vida perceptiva. Este potenciamiento involucra tanto el factor absolutamente expresivo de la emoción cuanto el aspecto cognitivo del percibir, a partir de la capacidad de reconocer imágenes. Los involucra en un sentimiento de intensificación de su vida y de bien-estar en la trama de las relaciones con el mundo y con los otros que lo componen. El sentimiento de la vida se hace más intenso y agradablemente leve precisamente a partir de esas experiencias de armonización en lo exterior y en lo interior, producidas por un impacto perceptivo memorable con propiedades estéticas elementales de objetos e imágenes. Impactos perceptivos que pasan no sin consecuencias, sino dejando huellas en la memoria. Precisamente de la elaboración imaginativa de estas trazas (en la memoria) nacen y toman su forma provisoria los primeros esquemas estéticos. Tales esquemas no serían posibles sin la contribución de una prestación imaginativa activa en la elaboración de imágenes de los elementos que hubieran funcionado como atractores estéti- cos y que funcionarán como puntos y uniones de un reticulado esquemático futuro (una red móvil de afinidad).

Consustancial al origen de lo estético, a la determinación de una actitud estética como un rasgo peculiar de la identidad humana, puede decirse que el vínculo de una circularidad virtuosa se establece entre las formas embrionarias de la experiencia estética típicas del desarrollo infantil y la primera formación de esquemas orientados y potenciados estéticamente. Presupuesto indudable para esta circularidad virtuosa es la sinergia que constituye el escenario de una experiencia atencional común. Polarizada hacia un atractor compartido, esta sinergia emocionalmente sintonizada favorece la familiarización no solo entre los actores sintonizados afectivamente que componen la escena, sino también con el objeto sin el cual dicha escena no existiría.

\section{AURA Y ESQUEMA}

1. Existe, entonces, la percepción de un aire de familia que precede a la participación de la experiencia humana en el horizonte del lenguaje, en la esfera articulada de significados como la gramaticalización del mundo. Sin esta precedencia pre-gramatical de una experiencia de familiaridad perceptiva, ni siquiera sería posible comprender los "parecidos de familia" de los que habla Ludwig Wittgenstein en las Investigaciones filosóficas (1953)

Comprender-verlos parecidos en el plano del lenguaje, detectando aspectos comunes entre palabras, expresiones y significados, no puede derivar de operaciones deductivo-inferenciales o de la intuición de unidades metalingüísticas lógicamente esenciales. Algo similar vale para la realidad sensible, donde captar similitudes como "parecidos de familia" tiene un valor perceptualmente feraz que, 
aunque se alimenta de indicios, affordances, referencias, no deriva de ellas. En esta fecundidad y abundancia, la actividad de percibir se configura como el ritmo de la respiración. El aire de familia viene en primer lugar inspirado y entonces se percibe como tal. En el presupuesto de una sintonización atencional y un intercambio expresivo con el exterior de un espacio denso en resonancias y entramado (atravesado por fibras que invierten la trama de la experiencia en forma de rastros de la memoria), el aire familiar fructíferamente percibido-inspirado se puede llamar de manera sintética un aire de familia "estético". Un aire, o bien un aura ${ }^{3}$, de estética que se alimenta del intercambio entre la propensión interna de la intencionalidad convergente y el polo atractor que llama a la convergencia sobre sí mismo hasta constituirla en una experiencia compartida. Un intercambio que ya podríamos llamar "expresivo" precisamente en virtud del hecho de que el objeto, una vez tomado como polo de la atención compartida, ya no está cerrado en sí, en su opacidad inmanente, sino hecho signo: un índice memorable de una experiencia que espera repetirse.

2. La tesis del desarrollo infantil temprano de los esquemas estéticos -incluso quizá antes de la llamada "revolución de los nueve meses" de la cual habla Tomasello (1999: 82-3)- es completamente intrínseca a la tesis más general relacionada con la irreductibilidad y la universalidad de la actitud estética humana y su relación estratégica con el desarrollo de una actitud cognitiva y ética. Para que una actitud estética se estabilice y se desarrolle a lo largo de todo el arco de la experiencia humana entendida globalmente, es decir, tanto en una dirección transtemporal como en un sentido transcultural, es

${ }^{3}$ Naturalmente, la noción de "aura” está tomada aquí de Benjamin (1936). Para más información y una actualización del concepto benjaminiano, véase Desideri 2013. decisivo que desde el aura de esteticidad propia de la interacción inicial madre-hijo se formen esquemas de valor estético capaces de orientar y favorecer experiencias cada vez más complejas, pero en cualquier caso marcadas por una síntesis entre la demanda emotiva y la discriminación cognitiva.

Como hemos argumentado en otra parte (Desideri 2011: 51-52), recordando las tesis del psicólogo neo-piagetiano Juan Pascual Leone (en particular 2006), sería precisamente el establecimiento de una circularidad entre procesos de atencionalidad exógenos y endógenos lo que genera esa experiencia perceptiva de la familiaridad que favorece la formación en nuestra mente de esquemas que bien podemos llamar "estéticos". Esquemas cuya característica principal sería la de una extrema flexibilidad e indeterminación, tanto desde el punto de vista de la referencia al objeto como desde el de la definición conceptual. Esquemas flexibles e indeterminados, pero precisamente por esto extremadamente capaces de englobar nuevos marcadores sobresalientes y, por lo tanto, de captar relaciones de afinidad entre configuraciones y aspectos de la realidad que son per se heterogéneos.

La baja y bajísima regularidad de tales esquemas, así como su indeterminación conceptual, los haría capaces de comprender y de reforzar los parecidos de familia entre fenómenos, atmósferas, objetos y eventos muy diversos entre sí en lo que hace a sus características objetivamente básicas y sus propiedades fenoménicas. Diferente, sin duda, en cuanto a las clases conceptuales de pertenencia, pero aún plausibles de entrar en una conexión virtual al compartir aspectos de tenor estético similares. En el papel de orientación heurística que desempeñan los esquemas estéticos en la exploración perceptiva del mundo, se revela su naturaleza activamente dinámica, su acción de manera proyectiva y anticipatoria en el entramado temporal de la 
experiencia (véase Desideri 2011: 56). La actitud estética confirma así ser una actitud intrínsecamente exploratoria, como insiste Nelson Goodman (1968: 241-244) que conecta de manera activa y potenciadora la dimensión emotiva y cognitiva.

En otro trabajo hemos mostrado cómo de la peculiaridad de los juicios estéticos, así como de su irreductibilidad a juicios del tipo puramente cognitivo o evaluativo, no se puede decir que sean ajenos a la funcionalidad operativa y reiterativa de los esquemas estéticos (Desideri 2017). De hecho, ésta los presupone y se origina a partir de ellos. Estando gobernados por una regularidad indeterminada, los esquemas estéticos actúan en el tejido de la experiencia, extendiendo desde el interior la dinámica perceptiva, la estructura del mundo, sacando a la luz nuevos niveles de realidad y nuevas capas de significado.

En coherencia con esta tesis, la actitud estética como una actitud transcultural específicamente humana puede caracterizarse por la potencialidad semántica de la indeterminación y de la anticipación respecto a las relaciones cognitivas y las actitudes estéticas. En particular, debido al funcionamiento cognitivamente indeterminado $y$ experimentalmente proyectivo que distingue los esquemas estéticos. Del funcionamiento efectivo de tales esquemas resulta, así, no solo la centralidad de la experiencia estética para la naturaleza humana, sino también su carácter estructuralmente anticipatorio. En otras palabras, precisamente activando esquemas de cierto tipo presentes en la memoria, la experiencia estética revela su carácter ejemplar, configurándose como experiencia y anticipación de la experiencia al mismo tiempo. También debido a esto, la "percepción refleja", cual la célula original de cualquier experiencia estética, tiende estructuralmente hacia el futuro.

\section{FUNCIÓN GENERAL DEL ESQUEMA Y ESPECIFICIDAD ESTÉTICA}

1. Aclarada, pues, la relevancia de la formación de esquemas en un contexto de familiarización perceptiva que prepara la formación de una actitud estética, ahora se hace esencial aclarar en qué medida el esquematismo estético difiere de otros tipos de esquematismo. Se trata, en breve, de pensar no solo en el origen, sino también en la legitimidad funcional de los esquemas específica e irreductiblemente estéticos. El origen y la legitimidad de los esquemas de naturaleza estética -es decir, de los esquemas que funcionan estéticamente conectando información emotiva y propiedades de objetos, encapsulando y orientando preferencias- solo pueden destacarse en su irreducible especificidad en el marco de la tesis más general, vale decir, de que cualquier relación cognitiva no puede prescindir de esos dispositivos de síntesis funcional que, al menos desde Kant, definimos como esquemas.

Contra aquellos que entienden la mediación del esquema como una interfaz innecesaria entre nosotros y el mundo, defendemos entonces la necesidad de presuponer el esquematismo a partir de su carácter cognitivamente operativo, es decir, de su consistir esencialmente en la recursividad de una función de conexión/selección y entre el input sensorial y el sistema/organismo que lo procesa.

Esto es lo que sostiene Frederic C. Bartlett (1932) en lo que es la recuperación más influyente del siglo Xx (junto a la de Piaget) de la noción de esquema en el contexto de una teoría psicológica del funcionamiento cognitivo de la mente: ${ }^{4}$ surge la necesidad de una

${ }^{4}$ Para la importancia de Bartlett en el contexto de la recuperación contemporánea de la noción de un esquema desde el punto de vista de una antropología cognitiva, véase Casson 1983. 
función esquematizadora para hacer frente a la relación entre la memoria y la nueva información sensorial. Remembering, de Bartlett, tiene un carácter eminentemente constructivo y los esquemas ${ }^{5}$ son expresión activa del carácter estructurante de la memoria, tanto desde el punto de vista de la acción como del de la percepción. Los esquemas, en cuanto "patterns activos" o "settings organizados” (Bartlett 1932: 213 y 201), realizan la función de organizar constructivamente las reacciones o las experiencias pasadas, a fin de mantener la estabilidad del sistema respecto a los desafíos ambientales.

En los esquemas se expresa, por lo tanto, una "forma de arreglo" con la realidad. Respondiendo a la demanda de una adaptación continua a los inputs externos, los "esquemas" bartlettianos no están en absoluto caracterizados por una rigidez y fijación. Por el contrario, se caracterizan por un desarrollo continuo, en el sentido de que "se modifican por cada nimia manifestación de cualquier experiencia sensorialmente notable" (Bartlett 1932: 200). Si, por un lado, el principio de regularidad prevalece en el esquema, por el otro, tal prevalencia está relacionada con el principio de variación, en cuanto es funcional a la necesidad de responder a desafíos cognitivos siempre nuevos y cada vez más complejos y, por lo tanto, a la misma estabilidad y supervivencia de un sistema organizado. Esto, por supuesto, también vale para un sistema organizado y autorreflexivamente consciente como el humano. También en este caso, los esquemas están activos, "actúan" por debajo del umbral de una conciencia autorreflexiva. Su operatividad, en otras palabras, puede

\footnotetext{
${ }^{5}$ Como se sabe, Bartlett (1932: 200-201) usa el término "esquema" aunque no le gusta mucho, al encontrarlo "demasiado definido y aproximado al mismo tiempo". Sobre la complejidad y actualidad de la noción bartlettiana de esquema, véase especialmente Waggoner 2011 y 2013.
}

ser válida en la medida en que está implicada en las relaciones cognitivas a partir de dinámicas perceptivas que incorporan la reflexividad, hasta el punto de que su reflexividad interna coincide con el principio cuasi-finalista de su funcionamiento.

Los esquemas funcionan como si fueran conscientes de su selectividad constructiva y sensibilidad al cambio ${ }^{6}$. Por esta razón, aceptando la intuición fundamental de Bartlett, las modulaciones esquemáticas de respuesta en el horizonte de la percepción y/o en el plano de acción (es famoso el ejemplo del tenis empleado por Bartlett) podrían verse como la articulación interna de la memoria del sistema: esa articulación que recuerda, en primer lugar, a la chance de orientarse cognitivamente en relación con el exterior. El esquema se impone como un recurso cognitivo y operativo constantemente abierto a una dialéctica entre asimilación y adaptación (para usar los términos de la teoría del esquema de Piaget) frente a la realidad. Su fuerza radica en la capacidad de mantener unidos -gracias a la prevalencia del principio de regularidad en su constituirse- la identidad y la variación, la estabilidad y el cambio. Esto, en alternativa tanto a las soluciones internalistas del tipo asociacionista como a las soluciones externalistas del tipo conductista (que generalmente giran en torno al modelo de estímulo-respuesta).

2. En términos más generales, una teoría del esquematismo caracterizada en un sentido dinámico-operativo e interaccionista puede constituir una respuesta eficaz al escepticismo. Una teoría tal corrobora, de hecho, el punto de vista del realismo e implica, en cualquier caso, la necesidad de suponer un externalismo moderado

${ }^{6}$ Como señala Ulrich Neisser (1976: 56) al insistir en el carácter de "proceso activo" del esquema, es "un modelo de acción, así como un modelo para la acción" y, por lo tanto, "el esquema no es solo el plan sino también el ejecutor del plan". 
cuando se trata de dilemas relacionados con la estructura de la percepción. Podemos referirnos, por ejemplo, al carácter constructivointerpretativo de la percepción en el sentido de Nelson Goodman (véase Marchetti 2006: 66-73), o a su carácter de movimiento para entrar en el juego lingüístico de dar y tener razones, como es el caso del inferencialismo semántico de Robert Brandom. ${ }^{7}$

3. Ya en Kant está del todo claro que el uso de una doctrina del esquematismo está estrictamente conectado con la necesidad de evitar el escepticismo en el marco de una teoría del conocimiento. No solo al nivel de Crítica de la razón pura, ${ }^{8}$ sino también al nivel de la Crítica de la facultad de juzgar. Del todo explícito a este respecto es el $\$ 21$, Si se puede presuponer con razón un sentido común, que parte de la cuestión de la comunicabilidad universal del conocimiento y los juicios, sin la cual no sería concebible ningún acuerdo con el objeto. Sin tal acuerdo, de hecho, nada quedaría sino "un juego meramente subjetivo de las facultades representativas" (KdU: B 65), como quiere el escepticismo. Además, como ya se observó en la parte de la primera edición de la Crítica de la razón pura dedica-

\footnotetext{
${ }^{7}$ Brandom (1994: 234-235) retoma la noción de "espacio de razones" del importante ensayo de Wilfrid Sellars (1954). Acerca del modo en el que Sellars reinterpreta lo que él llama "la oscura doctrina kantiana del esquematismo", véase Sellars 2002: 277 y passim. Para una discusión interesante de la noción de "espacio razones" en Robert Brandom y John McDowell, véase Iglesia 2013: 112-122. Otra fortaleza del análisis desarrollado por Jennifer Church radica en tener en cuenta la cuestión de "percepción estética" (Iglesia 2013: 227-264). Sobre la necesidad de revisar la noción del "espacio de razones" y el expresionismo racionalista de Brandom a la luz de una teoría del expresionismo estético, véase también Desideri 2011: 81-85.

${ }^{8}$ Donde el nexo entre las páginas atormentadas del esquematismo trascendental (también en el controvertido pasaje de la primera a la segunda edición) y la posibilidad de emitir juicios sintéticos a priori es absolutamente evidente (hasta el punto de que, si el esquematismo falla, se abre la brecha entre la lógica pura de los juicios analíticos y el carácter meramente empírico de los sintéticos).
}

da a la Deducción, es precisamente el elemento de necesidad lo que vincula el concepto al objeto para impedir que nuestro conocimiento esté determinado "al azar o arbitrariamente, sino a priori de una manera definida" ( $K r V:$ A 104). Lo que es interesante para nuestra discusión, sin embargo, es que algún elemento o aspecto de esta necesidad, en el desarrollo de la preocupación antiescéptica a partir de la cual comienza el $\$ 21$ de la tercera Crítica, llega a involucrar "esa proporción que corresponde a una representación (mediante la cual se nos da un objeto), para darlo a conocer" (KdU: B 65). Sin esta condición -observa Kant- "el conocimiento, en tanto que efecto, no podría surgir" (KdU: B 65). De hecho, la "disposición al acuerdo", que se expresa en esta proporción, es incluso la "condición necesaria de la comunicabilidad universal de nuestro conocimiento" (KdU: B 66) presupuesta en cada lógica y en cada principio de saber que uno no quiere rendirse al escepticismo.

Condición de toda lógica del conocimiento, la "disposición al acuerdo" lo es, sin embargo, en cuanto Stimmung: resonar del acuerdo. Prerrequisito necesario de la regla conceptual que articula el conocimiento, en primer lugar, en el gobierno del esquematismo "objetivo", la "disposición al acuerdo" en cuanto relación entre las facultades cognoscitivas se lleva a cabo expresamente en el juego solidario de una revitalización recíproca (inneres Verhältnis zur Belebung) que solo se puede sentir. Entre Stimmung y Gefühl, entre la entonación afectiva (acuerdo) y el sentimiento, existe por lo tanto una relación necesaria, y en esta relación se supone "lógicamente" un sensus communis. Pero en la necesidad de esta suposición, de esta co-implicación entre sentimiento y cognición, ¿son concebibles los esquemas? ¿Y bajo qué condiciones? 


\section{ESQUEMA E IMAGEN}

1. Al teorizar la noción de esquema como expresión funcional de regularidad en el contexto del trabajo constructivo de la memoria, de su activo organizar el material filtrado por la percepción, Bartlett (1932) distingue "esquema" de "imagen". Mientras el esquema actúa en función del continnum de una serie de acciones o reconocimiento, ${ }^{9}$ la imagen surge como una ruptura, interrumpiendo el dominio de la regularidad esquemática. A la naturaleza cognitivamente generalizadora del esquema, la imagen opone la particulari$\operatorname{dad}^{10}$ de una experiencia que reclama sus derechos. Las imágenes son "un dispositivo para extraer elementos de esquemas" (Bartlett 1932: 219), son capaces de aumentar "la posibilidad de variabilidad en la reconstrucción de estímulos y situaciones del pasado" y de "superar la cronología de las presentaciones" (ibid.). En la imagen, por lo tanto, se afirma la emergencia "espacial" del presente, en cuanto es capaz, en su eventual discontinuidad, de reorganizar y reagrupar el tiempo pasado alrededor de la exterioridad de su persistir presente. El espacio internamente organizado del esquema (su constituir una "figura" en cuanto producto de la imaginación) en virtud del surgimiento de la imagen estaría así ordenado al continuum de la experiencia: a la posibilidad trascendental de su flujo (véase Malnick 2001). ${ }^{11}$

\footnotetext{
9 “Conducir un automóvil, pintar una imagen, subir escaleras o recordar su número de teléfono son actividades directas que funcionan como un flujo continuo, sin que haya una autorreflexión en ellos. Requieren la coordinación inconsciente de una serie de actos en el tiempo y el espacio a través de una cierta armonía con el medio ambiente" (Waggoner 2013: 559).

${ }^{10}$ Véase Waggoner 2013: 561-562 y especialmente 2011, donde el autor desarrolla una síntesis interesante entre las perspectivas de Bartlett y Vygotsky.

${ }^{11}$ Partiendo de una lectura cognitivista y constructivista de la exposición de la deducción contenida en la primera edición, Malnick mantiene aquí una consistencia sustancial y continuidad entre las dos exposiciones.
}

En la imagen, en la unidad comprensible de la síntesis que expresa, el tiempo se vuelve más bien actualidad: viva presencia. Cada experiencia estética -de la más elevada a la más ordinaria-, por lo tanto, gira en torno a esta actualidad de la imagen. En la forma de una conciencia intensificada, de una conciencia que emerge y se destaca de la trama del percibir (del intercambio real que significa), la experiencia estética es la experiencia de una unidad de imagen como una presencia viva, expresión de una figura que curva el fluir de la experiencia y la dinámica perceptiva subyacente en la espacialidad del instante que trasciende el continnum. El tiempo-espacio de la imagen puede, entonces, bien llamarse "instantáneo", precisamente porque se manifiesta en el tejido de la vida perceptiva interrumpiendo la rutina, casi libre de las restricciones del pasado y la memoria.

$\mathrm{Al}$ carácter restrictivo del esquema objetivo, a su estar en función del continuum, la experiencia estética opondría así la libertad anárquica de la imagen, en cuanto despliegue energético de una pura presencia, a la naturaleza vinculante del esquema objetivo, a que sea una función del continuo. El problema, en este punto, es comprender si y cómo una "lógica", por así llamarla, instantánea de la imagen -una lógica paradojal, sin embargo- puede incorporar algo de la regularidad y la recursividad del esquema. Si a la pregunta sobre esta posibilidad le damos una respuesta completamente negativa, la misma experiencia estética podría entregarse a la inefabilidad: al carácter inefable de un instante puntual que convertiría en completamente incomunicable ese tipo de experiencia, vaciándola de cualquier relación con la esfera compartida y basalmente común en el juicio. Pero, ¿se concebiría una experiencia estética sin conexión con la comunidad de jueces? ¿No se volvería, así, el mismo sensus aestheticus irremediablemente privado? 
2. En el contexto de estas preguntas y dentro del marco de una distinción lógica entre esquema e imagen, se repite en toda su fuerza teórica la exigencia kantiana de diferenciar el esquematismo subyacente a los juicios estéticos del esquematismo que en el $\$ 9$ de la Crítica de la facultad de juzgar es llamado por primera vez "objetivo” (KdU: B 10). La limitación de acción de este último, como lo especifica Kant en varias ocasiones, es ofrecida por el intelecto como una producción espontánea de reglas de unificaciónestructuración de lo múltiple sensorial-perceptivo. Aquí el complejo esquemático, la red que diseña, tanto a priori como durante el curso de la experiencia, no es más que el reverso de la trama de la objetividad.

El esquema "cognitivo" (podemos especificar ciertamente así el “esquema objetivo" del que Kant habla en el \$9) funciona y es universalmente comunicable en cuanto se ajusta en acuerdo al objeto. En cuanto nodo en la trama de la objetividad, el esquema se confirma como expresión de una ontología compleja o, si se quiere, como una expresión de un realismo crítico. En el "esquema objetivo" o "cognitivo", el acuerdo con el objeto, que desde el punto de vista de una lógica del conocimiento es también acuerdo en el objeto (inmanente en su constitución), constituye, en efecto, la variable incognita (abierta a la confirmación de la experiencia) de la estructura esquemática: el slot abierto con respecto a la regularidad conceptual que vincula ese proceder "subsumidor" que para Kant caracteriza el juicio determinante $y$, en consecuencia, el mismo funcionamiento del esquema objetivo.

3. Reaparece aquí en toda su relevancia uno de los lanzamientos contemporáneos más agudos de la noción de un esquema, el cual está definido a partir del trabajo fundamental de Bartlett. Es en referencia a la teoría de los frames, elaborada por Marvin Minsky, uno de los más grandes teóricos contemporáneos en el campo de la investigación sobre inteligencia artificial, a partir del famoso ensayo A framework for Representing Knowledge (1974). ${ }^{12}$ Recordando la noción bartlettiana de esquema y la noción kuhniana de paradigma, Minsky (1974: 213) entiende el frame como una estructura seleccionada por la memoria para enfrentar nuevas situaciones y lo define como una "red de nodos y relaciones". La estructura de cada frame se compone entonces de top levels, intrínsecamente estables y ya fijos, y niveles inferiores, "terminales" o slots, que deben llenarse "de ejemplos y datos específicos". El funcionamiento de cada frame consiste, por lo tanto, en el matching process que pretende asignar a cada terminal valores que tengan el carácter de ser novedosos y, al mismo tiempo, ser consistentes con los marcadores/selectores ya definidos.

La apuesta cognitiva y operativa se refiere, entonces, a la capacidad del frame individual y del frame-system en los que cada frame está inserto, para tratar la sorpresa dentro del marco de la información ya adquirida. La peculiaridad ventajosa del esquema concebido como un marco en el sentido minskyano consistiría, así, en equilibrar un marco de estabilidad con permeabilidad al novum. La confirmación de una naturaleza epistémica actuaría, por lo tanto, como una ampliación de las reglas iniciales (el nivel top level mencionado por Minsky).

\section{DE LOS IMÁGENES-ESQUEMA A LOS ESQUEMAS ESTÉTICOS}

1. Dada esta última peculiaridad, podemos también proyectar el problema minskyano de los frames en las páginas kantianas, para

${ }^{12}$ Minsky luego desarrolló lo que se presenta brevemente en este ensayo en la famosa Sociedad de la Mente (véase Minsky 1986). 
releer así la cuestión del esquematismo libre de la imaginación -de un esquema, es decir, que en su aplicación presupone precisamente una "norma indeterminada" (véase $K d U$ : $\$ 22$ ) ${ }^{13}$ - en términos de la relación entre los top levels (el nivel en el que la nueva forma de ejemplo debe subsumirse) y los terminals. Surge la posibilidad de pensar (de hacer plausiblemente imaginable) la relación entre los top levels y los terminals en términos de un esquematismo capaz de incorporar en su procedimiento y en su estructura funcional tanto el carácter recursivo de la regularidad como la anarquía eventual de la imagen. En la dirección del desarrollo de esta cuestión van las últimas reflexiones de Emilio Garroni quien introduce, a este respecto, la noción de esquema-imagen.

2. En sus últimos escritos, Garroni (2003; 2005: 57-67) observa con mucha agudeza cómo la distinción establecida por Kant entre "esquematismo libre (subjetivo) y esquematismo objetivo" conduce a una "revisión profunda" de toda la cuestión y, en particular, del modo en el que se trata la cuestión del esquematismo dispuesto en la primera Crítica. El razonamiento de Garroni se articula en dos movimientos esenciales. En primer lugar, observa cómo la libertad de la imaginación no corresponde a una anomia anárquica: "[S]i bien esquematiza sin conceptos determinados, no por esto esquematiza sin conceptos indeterminados, es decir, en relación con la misma legalidad en general del intelecto" (Garroni 2003: 84). De ahí, deriva un papel del esquematismo libre de la imaginación en la génesis misma del esquema empírico. Así, uno puede comprender "el modo nativo de funcionamiento de la imaginación" (ibid. 85)

\footnotetext{
${ }^{13}$ Como Kant observa con clara lucidez en la Nota general a la primera sección de la analítica, "que la imaginación es libre y cumple con las leyes, es decir, que implica autonomía, es una contradicción” (KdU: B 69). El hecho es que sin pensar en esta "contradicción" desde adentro, incluso la estética es impensable. A menos que se la quiera reducir a un sustituto híbrido del discurso filosófico.
}

mucho más allá del ámbito específico de la experiencia estética, o en la formación de una imagen interna que, por un lado, tiene las características de indeterminación y, por el otro, tiene rasgos relevantes o relevantizables como patrones de reconocimiento (véase Krausser 1976). Si el primer movimiento de Garroni revela la fecundidad cognitiva de la imagen-esquema, el segundo se refiere a su apertura constitutiva a exhibiciones-representaciones esquemáticas y simbólicas. Por un lado, entonces, cada esquema-imagen sería irreducible a la concreción perceptible de la figura, ${ }^{14}$ por el otro, constituiría su posibilidad interna. En términos kantianos, la imagen esquema proporcionaría la condición de cada "exhibición simbólica" y, por lo tanto, del procedimiento analógico-reflexivo a partir del cual se forma el símbolo. ${ }^{15}$

3. Con este perfil puramente interno, si no internalista, la imagenesquema garroniana aún no tiene las características del esquema estético. Una "típica"16 de los esquemas estéticos combinados con la tesis de su irreductibilidad tanto en el orden expresivorepresentativo de la imagen simbólica cuanto en lo puramente interno del imagen-esquema puede ser pensado con la condición de que no se abstraigan su génesis y su funcionamiento del tenor emotivo que permea varios niveles de la dinámica de la percepción. Sobre esta base, de hecho, puede considerarse la hipótesis de un

\footnotetext{
${ }^{14}$ Sobre este pasaje, véase Garroni (2003: 86-88), donde el autor, analizando la dialéctica interna de cada figura, se refiere al importante ensayo de Di Giacomo (1999).

${ }^{15}$ Para una lectura sesuda del esquematismo kantiano, véase el reciente e importante estudio de Lidia Gasperoni (2016). Acerca de la cuestión del esquema, desde Kant hasta la filosofía contemporánea, cf. los ensayos recogidos en Asmuth \& Gasperoni (2017).

${ }^{16}$ Se emplea aquí el término "típica" en analogía con el "típico del juicio práctico puro" definido en la Crítica de la razón práctica (KpV: A 119-126).
} 
mecanismo genético estético como una síntesis entre disposiciones enraizadas en el sistema de las emociones primarias y las funciones cognitivas superiores (véase Desideri 2016). En el carácter epigenéticamente emergente de esta síntesis, el tenor emotivo de la vida perceptiva está necesariamente involucrado, incluyendo las localizaciones corpóreas de los estados emocionales.

Lo que proponemos aquí con el término "esquemas estéticos" se diferencia, por lo tanto, de los image schemas definidos por George Lakoff (1987) y Mark Johnson $(1987,2007)$ en términos de estructuras básicas de la experiencia sensoriomotriz. ${ }^{17}$ En comparación con estos últimos, los esquemas estéticos son "subjetivos" en un sentido diferente, ya que involucran la corporeidad de una manera mediada, es decir, desde el punto de vista de los efectos que se sienten en el impacto perceptivo con los atractores atencionales estéticamente densos.

En el contexto de esta hipótesis, podemos pensar en la constitución de esquemas estéticos a partir de la unidad de imágenes percibidas como cognitivamente indeterminadas, semánticamente densas y clasificadas (indexadas) emocionalmente. Por este motivo, los esquemas estéticos representan un tertium entre los esquemas subjetivos [embodied] y los esquemas objetivos [cognitivos]. La regularidad indeterminada que distingue el trabajo de la imaginación en su

\footnotetext{
${ }^{17}$ Para Johnson, “un esquema de imagen es un patrón dinámico y recurrente de interacciones organismo-medio ambiente" (2007: 136) y constituye "un nivel emergente de significado preverbal y sobre todo inconsciente" (ibid. 144). A este tipo de esquemas encarnados pertenecen estructuras de "acoplamiento no representativo con el mundo" como el Contenedor, la Verticalidad, la Fuerza compulsiva, la Escalaridad o el esquema SOURCE-PATH-GoAL. En una dirección similar se orienta la teoría de una génesis del esquema-prototipo kinestésico desarrollada por Alberto Peruzzi en 1999 y 2006.
}

formación temprana siempre está emotionally tuned, sintonizada emocionalmente, mientras que la relación entre el top level y el terminal es, en ellos, intrínsecamente móvil y elástica. Esto facilita el matching process, la flexibilidad y la expansividad de los esquemas estéticos y, por lo tanto, su capacidad de orientación pre- y metacognitiva, descubriendo siempre (en condiciones apropiadas) nuevos niveles de realidad y nuevas dimensiones de experiencia.

Partiendo de experiencias prototípicas (por ejemplo, la de la cara de la madre o el juguete en una escena de atención conjunta), el esquema estético se forma por el sentimiento-descubrimiento de determinadas propiedades del objeto o de felt qualities (Johnson 2007: 41) a las que con derecho se puede llamar estéticas. Cualidades sentidas y de algún modo disentangled ${ }^{18}$ de unidades de imagen (aspectos y objetos del mundo percibidos), precisamente mediante esos efectores de comunicación constituidos por los marcadores emocionales que incorporan. A la luz de esto, los términos premodernos de reflexión estética como los de unitas in varietate, proportio, integritas, claritas, symmetria, consonantia/dissonantia, concinnitas reclaman su actualidad. En la connotación operativa y orientadora de cada una de estas nociones, podemos ver el operar de reglas indeterminadas donde la apertura de la apercepción sensible es constitutiva de su formación y funcionamiento en un sentido inequívocamente estético.
${ }^{18}$ Sobre el problema del disentangling dentro de las inferencias perceptivas desde el punto de vista de modelos neurales, véase Olshausen 2014. 


\section{REFERENCIAS}

AlBerTAZZI, Liliana (ed.) (1999), Shapes of Forms: From Gestalt Psychology and Phenomenology to Ontology and Mathematics (Amsterdam: Kluwer).

ASMUth, Christoph \& GASPERONI, Lidia (2017), Schemata (Würzburg: Königshausen u. Neumann).

BARTLETT, Frederic C. (1932), Remembering: A Study in Experimental and Social Psychology (Cambridge: Cambridge University Press).

Benjamin, Walter [1936] (2012), Das Kunstwerk im Zeitalter seiner technischen Reproduzierbarkeit, Werke und Nachlass. Kritische Gesamtausgabe, t. 16, ed.. de Burkhardt Lindner con la col. de Simon Broll y Jessica Nitsche (Berlín: Suhrkamp). [Ed. italiana: L'opera d'arte nell'epoca della sua riproductibilità tecnica, tre versioni (1936-39), ed. de Fabrizio Desideri, trad. de Massimo Baldi, Roma: Donzelli, 2012].

BRANDOM, Robert B. (1994), Making It Explicit. Reasoning, Representing and Discursive Commitment (Cambridge (MA): Harvard University Press).

CASson, Ronald W. (1983), "Schemata in Cognitive Anthropology", Annual Review of Anthropology, 12: 429-462.

CHurch, Jennifer (2013), Possibilities of Perception (Oxford: Oxford University Press).

DESIDERI, Fabrizio (2011), La percezione riflessa. Estetica e filosofía della mente (Milán: Raffaello Cortina).

(2013), “Aura ex machina”, Rivista di Estetica, 52: 33-52.

(2016), "Epigénesis y coherencia del mecanismo estético", Boletín de Estética, 35: 7-33

_ (2017), "Otra deducción de los juicios estéticos. Por una superación de la dicotomía entre hechos y valores”, Boletín de Estética, 40: 734.
Di Giacomo, Giuseppe (1999), Icona a arte astratta (Palermo: Centro internazionale studi di estetica).

GARRONI, Emilio (2003a), "Immagine interna, figura-segno e lo schematismo kantiano", en Garroni (2003b: 76-88)

__ (2003b), L'arte e l'altro dall'arte. Saggi di estética e di critica (RomaBari: Laterza).

_ (2005), Immagine Linguaggio Figura. Osservazioni e ipotesi (RomaBari: Laterza).

GASPERONI, Lidia (2016), Versinnlichung. Kants transzendentaler Schematismus und seine Revision in der Nachfolge (Berlín: De Gruyter).

Gazzaniga, Michael S. \& Mangun, George R. (eds.) (2014), The Cognitive Neurosciences (Cambridge MA: The MIT Press).

Goodman, Nelson (1968), Languages of Art: An Approach to a Theory of Symbols (Indianapolis: Bobbs-Merrill).

HaRdCASTLE, Valerie Gray (1997), "Attention versus Consciousness: A Distinction with a Difference", Cognitive Studies, 4, 3: 56-66.

JoHnson, Mark (1987), The Body in the Mind: The Bodily Basis of Meaning, Imagination, and Reason (Chicago (IL): The University of Chicago Press).

(2007), The Meaning of the Body. Aesthetics of Huan Understanding (Chicago (IL)-Londres: The University of Chicago Press).

KANT, Immanuel $(\mathrm{KrV})$, Kritik der reinen Vernunft (Fráncfort del Meno: Suhrkamp) [1781-1787] 1976.

_ $(K p V)$, Kritik der praktischen Vernunft (Fráncfort del Meno: Suhrkamp) [1788] 1976.

_ $(K d U)$, Kritik der Urtheilskraft (Fráncfort del Meno: Suhrkamp). [1790] 1981.

Krausser, Peter (1976), "Kant's Schematism of the Categories and the Problem of Pattern Recognition”, Synthese, 33, 1: 175-192. 
LAKOFF, George (1987), Women, Fire, and Dangerous Things: What Categories Reveal about the Mind (Chicago IL: The University of Chicago Press).

MALNICK, Arthur (2001), "Categories, Logical Functions, and Schemata in Kant”, The Review of Metaphysics, 54, 3: 615-639.

MARChetTi, Luca (2006), Arte ed estética in Nelson Goodman (Palermo: Centro Internazionale studi di estetica).

MinsKY, Marvin (1974), “A Framework for Representing Knowledge”, memo $\mathrm{n}^{\circ} 306$, Massachusetts Institute of Technogy, Artificial Intelligence Laboratory (repr. en Winston 1975: 211-277).

_ (1986), The Society of Mind (New York: Simon \& Schuster). [Ed. italiana: La società della mente, trad. de Giuseppe Longo, Milán: Adelphi, 1989].

NEISSER, Ulric (1976), Cognition and Reality: Principles and Implications of Cognitive Psychology (San Francisco (CA): Freeman).

Olshausen, Bruno A. (2014), "Perception as an Inference Problem", en Gazzaniga \& Mangun (2014: 295-304).

PAsCuAl-Leone, Juan (2006), "Mental Attention, not Language, may explain Evolutionary Growth of Human Intelligence and Brain Size”, Behavioral and Brain Sciences, 29, 1: 19-20.

PERUZZI, Alberto (1999), “An Essay on the Notion of Schema”, en Albertazzi (1999: 191-243).

Sellars, Wilfird (1954), “Some Reflections on Language Games”, Philosophy of Science, 21, 3: 204-228 (también en Sellars 2007: 28-56).

_ (2007), The Space of Reasons: Selected Essays of Wilfrid Sellars, ed. by K. Scharp \& R. B. Brandom (Cambridge (MA)-London: Harvard University Press).

Stenner, Paul (ed.) (2011), Theoretical Psychology: Global Transformations and Challenges (Concord: Captus University Publications).

STERN, Daniel N. (1985), The Interpersonal World of the Infant (London: Karnac Books). [Edición italiana: Il mondo interpersonale del bambino, trad. de Alessandro Biocca y Lucia Marghieri Biocca, Torino, Bollarti Boringhieri, 1987].

Tomasello, Michael (1999), The Cultural Origins of Human Cognition (Cambridge MA): Harvard University Press). [Ed. italiana: Le origini culturali della cognizione umana, trad. de Maurizio Riccucci, Bolonia: Il Mulino, 2005].

(2009), Le origini della comunicazione umana, trad. de Salvatore Romano (Milán: Raffaello Cortina). [Ed. original: Origins of $\mathrm{Hu}$ man Communication, Cambridge (MA), The MIT Press, 2008]

WAGONER, Brady (2011), "Meaning Construction in Remembering: A Synthesis of Bartlett and Vygotsky", en Stenner (2011: 105-114)

_ (2013), "Bartlett's Concept of Schema in Reconstruction", Theory \& Psychology, 23, 5: 552-575.

Winston, Patrick Henry (ed.) (1975), The Psychology of Computer Vision (Nueva York: McGraw-Hill).

WitTGensteIn, Ludwig (1953), Philosophische Untersuchungen / Philosophical Investigations, ed. de G. E. M. Ascombe (Oxford: Blackwell). 